\title{
APROXIMACIONES A LA DESCENTRALIZACIÓN COMO FORTALEZA EN LA TRANSICIÓN NORMATIVA DE LOS POT Y LOS GOBIERNOS MUNICIPALES ${ }^{*}$
}

\author{
Jorge Eduardo Vásquez Santamaría* \\ Recibido: Mayo 23 de 2016 \\ Aprobado: Junio 21 de 2016
}

\begin{abstract}
RESUMEN
El artículo primero describe las generalidades de la aparición de los Planes de Ordenamiento Territorial (POT) en Colombia y la forma como la legislación fue prorrogando su adopción a cargo de los municipios, un proceso que definió para esas entidades territoriales la obligación de adoptar el instrumento técnico normativo como reglamentación de la planeación territorial en el marco de la autonomía promovida por la descentralización. De ello que se dé lugar a la descentralización como figura que fortalece el proceso de revisión, formulación, diseño y adopción del POT en la primera transición vivida por los municipios ante el vencimiento del mínimo establecido por la ley para adoptar la nueva reglamentación, se articule el rol de los principios para el ejercicio de las competencias de ordenamiento territorial, y se proponga cómo el POT es la reglamentación que recoge la dispersión de competencias que el ordenamiento jurídico delega en el Municipio como encargado de la planeación local.
\end{abstract}

Palabras clave: POT, Municipio, descentralización, competencias.

\footnotetext{
* Resultado final del proyecto de investigación "Medellín y las transiciones sociojurídicas para la ordenación del territorio: Segunda oportunidad para los Planes de Ordenamiento Territorial de las ciudades en Colombia", adscrito al Grupo de Investigaciones Orbis Iuris de la Facultad de Derecho de la Fundación Universitaria Autónoma de las Américas, en la línea de investigación "Derecho, conflicto e internacionalización".

** Abogado y Magister en Derecho de la Universidad de Medellín. Especialista en Derecho Administrativo de la Universidad Pontificia Bolivariana. Especialista en Docencia Investigativa Universitaria de la Funlam. Docente Investigador del Grupo de Investigaciones Orbis Iuris de la Facultad de Derecho de la Fundación Universitaria Autónoma de las Américas.georgevas19@hotmail.com,jorgevasquezsantamaria@outlook.com
} 


\section{APPROACHES TO DECENTRALIZATION AS STRENGTH IN THE NORMATIVE TRANSITION OF THE POT AND MUNICIPAL GOVERNMENTS} ABSTRACT

The article describes the generalities of the Land Management Plans (POT) in Colombia and how the legislation was extending its adoption by the municipalities; a process that entitled these territorial entities to adopt the technical normative instrument as a regulation of territorial planning within the framework of autonomy promoted by decentralization. This results in decentralization as a figure that strengthens the process of review, formulation, design and adoption of the POT in the first lived transition by municipalities before the expiry of the minimum established by law to adopt the new regulation and the articulation of the role of the principles for the exercise of the competencies territorial classification. Also, it promoted the POT as a regulation, which reflects the dispersion of powers that the law delegated to the municipality in charge of local planning.

Keywords: POT, municipality, decentralization, competencies

\section{ABORDAGENS À DESCENTRALIZAÇÃO COMO FORTALEZA NA TRASIÇÃO NORMATIVA DOS PDOT E OS GOVERNOS MUNICIPAIS \\ RESUMO}

O primeiro artigo descreve a visão geral do surgimento de planos de ordenamento terrritorial (PdOT) na Colômbia e como a legislação foi adiando sua adoção por parte dos municípios, um processo definido para estas entidades territoriais chamadas a tomar o instrumento técnico normativo como a regulação do planejamento territorial, no âmbito da autonomia promovido pela descentralização. Por esta razão se dê a descentralização como uma figura que fortalece o processo de revisão, formulação, desenho e adopção do PdOT na primeira transição vivida pelos municípios ante do termo do mínimo estabelecido por lei para adotar a nova regulamentação, articula o papel dos princípios para o exercício das competências do ordenamento territorial, e propôs que o PdOT seja a regulamentação que reflete a dispersão de competências que a lei delega ao município responsável pelo planejamento local.

Palavras-chave: POT, Município, descentralização, competências. 


\section{INTRODUCCIÓN}

Con la expedición de la ley 388 de 1997, conocida como ley de desarrollo territorial, aparece para el Municipio como entidad Político Administrativa fundamental de la descentralización territorial en Colombia (Constitución Política, 1991: Artículo 311) la obligación de formular Plan de Ordenamiento Territorial (POT), instrumento normativo en el cual se concentra la planeación físico territorial y ambiental de las jurisdicciones municipales.

Con la tarea de formular POT termina el proceso por medio del cual se debían remplazar los Planes de Desarrollo Municipal regulados por la ley 9 de 1989, instrumentos que previos a la Constitución Política de 1991 concentraban la reglamentación sobre la planeación territorial, ambiental, social y económica, los cuales fueron en parte suplidos por los Planes de Desarrollo regulados por la ley 152 de 1994, y que posteriormente debían ceder ante la obligación legal de formular POT.

Específicamente el remplazo de los Planes de Desarrollo Municipal de la ley 9 de 1989 se avizora entre los objetivos previstos en el artículo 1 de la ley 388 de 1997, entre los que se dispone la armonización y actualización de las normas de esta nueva legislación con las disposiciones de la ley 9 de 1989 pero también con las propias de la ley 152 de 1994, orgánica de Planes de Desarrollo, con la cual se dio cumplimiento a uno de los mandatos constitucionales previstos en el artículo 151 de la Carta Magna.

En el artículo 41 de la mencionada ley 152, el legislador dispuso para el caso de los municipios que junto a los planes de desarrollo debían contar con un plan de ordenamiento regido por las disposiciones especiales sobre la materia, para lo cual el Gobierno Nacional y los departamentos brindarían las orientaciones y apoyo técnico para la elaboración de los POT. Aquella disposición fue replicada por el artículo 9 de la ley 388 de 1997, y conforme con el artículo 21 de la misma normativa, ambos instrumentos deben guardar armonización, articulación y coherencia como normas reglamentarias para la planeación del Municipio:

El plan de ordenamiento territorial define a largo y mediano plazo un modelo de ocupación del territorio municipal y distrital, señalando su estructura básica y las acciones territoriales necesarias para su adecuada organización, el cual estará vigente mientras no sea modificado o sustituido. 
En tal sentido, en la definición de programas y proyectos de los planes de desarrollo de los municipios se tendrán en cuenta las definiciones de largo y mediano plazo de ocupación del territorio.

Para la adopción del POT la ley 388 de 1997 en el artículo 23 dispuso que en el plazo máximo de dieciocho meses a partir de la entrada en vigencia de la citada Ley, las administraciones municipales y distritales debían formular y adoptar los POT, los cuales, dependiendo de la carga demográfica asentada en la jurisdicción municipal podrían denominarse Plan de Ordenamiento Territorial - POT para los municipios con 100.000 habitantes o más, Plan Básico de Ordenamiento Territorial - PBOT para municipios con población entre los 30.000 y 100.000 habitantes, y Esquema de Ordenamiento Territorial - EOT, para municipios con menos de 30.000 habitantes (Ley 388, 1997: Artículo 9) sin que se excluyera ninguna de las entidades municipales de dicha obligación.

Siguiendo el artículo 23 de la ley 388, en caso de que un Municipio no cumpliera con la formulación del POT tenía la obligación de adecuar los contenidos de ordenamiento territorial del Plan de Desarrollo, y previó que en adelante, dentro de los seis meses anteriores al vencimiento de la vigencia del POT, las administraciones municipales y distritales deben dar inicio al trámite de formulación del nuevo plan, su revisión o ajuste.

La formulación de los POT en los municipios de Colombia debió acreditarse para inicios de 1998, no obstante el legislador se vio en la necesidad de ampliar por primera vez el término previsto en el artículo 23 de la ley 388 de 1997 hasta el 31 de diciembre de 1999 (Ley 507, 1999: Artículo 2), además de emplear todas las acciones de coordinación con la finalidad de alcanzar la adopción del instrumento reglamentario, y dejando la posibilidad que fueran las Oficinas de Planeación departamentales las encargadas de formular el proyecto de Acuerdo de POT para el caso de los municipios donde no fueran formulados, expresión fidedigna del principio de subsidiariedad en el ejercicio de las competencias de ordenamiento territorial previsto en el artículo 288 de la Constitución:

El Gobierno Nacional deberá implementar un plan de asistencia técnica a través de la coordinación interinstitucional de los respectivos ministerios y entidades gubernamentales, las Oficinas de Planeación de los respectivos departamentos y las Corporaciones Autónomas Regionales, para capacitar y prestar asistencia técnica en los 
procesos de formulación y articulación de los planes de ordenamiento territorial y en especial para los municipios que presenten mayores dificultades en el proceso. Las entidades gubernamentales involucradas en el proceso pondrán a disposición de los municipios y distritos los recursos de información y asistencia técnica necesarios para el éxito de los Planes de Ordenamiento Territorial (POT) (Ley 507, 1999: Artículo 4).

Posteriormente, por medio de la ley 546 de 1999, promulgada el 23 de diciembre, el legislador amplió el plazo de formulación de POT hasta el 30 de junio del año 2000, además de disponer un plazo de dos años contados a partir de la elección del primer Alcalde para los municipios erigidos con posterioridad a la citada ley, y de un año para los que se habían erigido dentro del año inmediatamente anterior a su entrada en vigencia (Ley 546, 1999: Artículo 26). Finalmente el Decreto 1686 de 2000 amplió el plazo hasta el 31 de diciembre del mismo año, solicitando a los Gobernadores proporcionar las instrucciones a las oficinas de planeación departamentales para que en coordinación con los municipios o distritos dieran lugar al proceso de elaboración, formulación y adopción.

La prórroga del término para la formulación y adopción del respectivo POT por cada Municipio planteó un reto en el ejercicio de la acción administrativa de las Administraciones Municipales. La reglamentación de la planeación físico territorial y ambiental de la jurisdicción se haría a partir de un instrumento técnico normativo que en últimas, más allá de remplazar los Planes de Desarrollo Municipal, empoderó al Municipio como entidad primaria de la estructura descentralizada nacional con una capacidad reglamentaria desde la cual se apuesta a la realización de los fines del Estado en el ámbito local. Desde entonces las Administraciones Municipales deben contar con un POT, el cual, desde las disposiciones del artículo 28 de la ley 388 de 1997, debe ser sometido a una revisión estructural al vencimiento de tres periodos constitucionales de la respectiva Administración; de lo contrario, el POT anterior mantendrá su vigencia. Sobre el proceso de revisión del POT el decreto 932 de 2002 comprendía:

(...) la reconsideración general o parcial de sus objetivos, directrices, políticas, estrategias, metas, programas, actuaciones y normas que, como consecuencia del seguimiento y evaluación de su implementación frente a la evolución de las principales características del 
ordenamiento físico-territorial del municipio o distrito, suponga la reformulación completa del correspondiente Plan, o la actualización o ajuste de sus contenidos de corto, mediano o largo plazo (...)

Sin embargo las disposiciones del Decreto 932 de 2002 fueron derogadas por el Decreto 4002 de 2004 que, siguiendo las normas de la ley 388 de 1997 dispone la oportunidad de revisar y ajustar los contenidos de largo, mediano o corto plazo de los POT, siempre y cuando haya vencido el término de vigencia de cada uno de ellos. Entre el 2012 y 2014, el cumplimiento de los doce años máximos de vigencia dispuestos por la ley 388 de 1997 a los POT obligaron a las autoridades municipales a emprender los procesos de evaluación, ajustes y reformulación para un nuevo y prolongado periodo, en medio de un país cuyas realidades han variado profundamente desde la promulgación de la Carta Política de 1991, la adopción del Estado Social de Derecho, y la asunción del poder judicial, a quien se encomienda cada vez con más fuerza la efectivización de Derechos Humanos, labor que adquiere relevancia si se tiene presente la dificultad que esto implica en una modalidad de organización de la vida social como la ciudad.

E1 POT, como referente que debe guiar el ejercicio de la voluntad política de la gobernabilidad municipal, y desde una visión deontológica, también la acción política de la ciudadanía asentada en dicha jurisdicción, emprendió un proceso de transición en las ciudades de Colombia en el cual se hace necesario enfocar la mirada en las fortalezas y debilidades promovidas por el ordenamiento jurídico para el Municipio.

Esas fortalezas y debilidades si bien se relacionan con el crecimiento demográfico, la estructuración de procesos de descentralización y consolidación de los gobiernos urbanos con poder de decisión, contratación y ejecución de obras de forma directa, y con la consolidación de las demandas de participación democrática de las organizaciones ciudadanas, trascienden hasta otras realidades como las secuelas del conflicto armado interno, al estudio profundo del funcionamiento de las distintas modalidades de descentralización administrativa en un marco Estatal, desde el cual se deben rehacer las razones que justifican el porqué de los gobiernos urbanos, y a la necesidad de políticas públicas como mecanismo de reconocimiento y amparo de derechos también a cargo de los gobiernos urbanos, todos fenómenos que han profundizado sus influencias en la ciudad a partir de las reglamentaciones del POT. 
Los procesos de transición de los POT, como norma municipal desarrollada por el ordenamiento jurídico para la gestión y ordenación de los territorios urbanos abrieron un escenario pertinente para indagar una forma de transición de vida social ajustada al gobierno urbano, como es el caso de la ciudad. Es así que el proyecto de investigación "Medellín y las transiciones sociojurídicas para ordenar el territorio: segunda oportunidad para los planes de ordenamiento territorial de las ciudades en Colombia", fue dividido en dos fases, siendo la primera una general y holística que trabajó desde la pregunta ¿Cuáles referentes sociojurídicos deben ser determinantes para la formulación, adopción y ejecución de los Planes de Ordenamiento Territorial (POT) ante la primera transición normativa impuesta por el ordenamiento jurídico colombiano?

Para llegar a la resolución de la pregunta entre los objetivos específicos se propuso describir las fortalezas y debilidades en la evolución del ordenamiento jurídico dispuesto para el ordenamiento del territorio municipal desde la Constitución Política de 1991, y explicar cuáles referentes sociojurídicos deben ser directrices generales para orientar el nuevo proceso de formulación de los POT, de las cuales la descentralización resulta como fortaleza y directriz del referente jurídico en el proceso de regulación del gobierno municipal colombiano.

De ello que el artículo describa la descentralización ajustada al escenario del ordenamiento territorial municipal, dando cuenta de las razones que la ubican como fortaleza a partir de los avances jurídicos y doctrinales que la defienden en la organización del Estado Social de Derecho. Para ello se explica por qué el municipio es la mejor expresión de la descentralización, lo que exige dar cuenta de cómo dicha entidad territorial ha debido sortear las débiles y conflictivas asignaciones legales de competencias a las entidades territoriales en un marco que lo dota de autonomía para hacerlas efectivas. Finalmente se devela como esa legislación diversa y dispersa es la que en la órbita municipal se concentra en el POT, al amparo de varios principios que superan los vacíos y ambigüedades para el cumplimiento de su función pública.

\section{LA DESCENTRALIZACIÓN COMO UNA FORTALEZA JURÍDICA PROMETEDORA PARA COLOMBIA}

Proponer la descentralización como una fortaleza para los gobiernos municipales implica partir de dicha institución como referente principialístico para el funcionamiento del Estado Social de Derecho, esto es, como plataforma para la organización y operatividad del Estado, 
superando la equidistancia frente a los procesos de crecimiento demográfico, la mera enunciación de la estructuración de procesos de descentralización y consolidación de los gobiernos municipales con ámbitos de decisión, la consolidación de las demandas de participación democrática, pero sobre todo, con los ejercicios eficientes, eficaces, responsables, transparentes, económicos y públicos de gobernabilidad.

La Constitución Política de 1991 estipuló en su artículo primero que "Colombia es un Estado social de derecho, organizado en forma de República unitaria, descentralizada, con autonomía de sus entidades territoriales", para designar con ello la definición de un nuevo periodo en el cual tanto la organización del Estado, como la potenciación de los medios para garantizar los derechos humanos encontrarían en el componente social del Estado de Derecho las razones para que varias de las características del Estado Liberal clásico y el Estado de Bienestar vieran en la descentralización las condiciones de una nueva y mejorada gobernabilidad de la Administración Pública.

El alcance principialístico de la descentralización es respuesta al histórico enfrentamiento de la modalidad de organización del Estado que ocupó a Colombia durante décadas, entre centralistas y federalistas, y como principio, abarca el contenido axiológico y jurídico político de una de las instituciones a partir de las cuales se organiza el Estado para procurar su mejor funcionamiento. Para comprender su alcance es pertinente acudir a la explicación de Libardo Rodríguez:

(...) encontramos dos órdenes de autoridades claramente diferenciadas: unas que manejan el Estado en su conjunto y otras que manejan o gobiernan las diferentes partes o secciones en que se subdivide aquel.

Esta dualidad de autoridades encuentra su fundamento en dos razones principales: por una parte la imposibilidad física de resolver todos los asuntos desde el centro del Estado, o sea desde la capital, y, por otra, la existencia de necesidades locales que deben ser resueltas por las mismas personas que habitan una parte del territorio y son quienes viven y sienten directamente esas necesidades.

La existencia de estas clases de autoridades da lugar a diferentes modelos de organización estatal y administrativa, según que las relaciones entre ellas sean de mayor o menor 
dependencia. Las clases de Estado que de allí resultan son el federal y el unitario. (2002: p. 46-47).

Manteniendo el modelo del Estado Unitario, la descentralización es el contrapeso a una cada vez más temida centralización que obstaculice la gobernabilidad del Estado en otras esferas diferentes a la central, y dificulte el cumplimiento de sus fines. Jena Philippe Pening Gaviria (2003) citando a Frégne (1986) explica la desecntralización como un proceso administrativo para mejorar la eficiencia en la organización del Estado, y como un proceso político que busca una repartición territorial de las responsabilidades, evidentemente respetando las grandes direcciones del Estado. Siguiendo a Baguenard (1994) comparte que la descentralización persigue en el nivel institucional la multiplicación de centros de decisiones que conlleven a una mayor eficacia en la gestión, los niveles superiores dejan las tareas operativas para concentrarse en áreas estratégicas; con la redistribución del poder se espera que las decisiones sean más acertadas, pues los gobernantes locales están más cerca del problema que se ha de resolver; y persigue el pluralismo político, pues se abre la posibilidad de que grupos sociales tradicionalmente excluidos accedan al poder local y/o como mínimo se crean nuevos espacios de participación para las comunidades. Finalmente Pening Gaviria define la descentralización como la transferencia de competencias "del aparato centralizado del Estado a los entes territoriales, dotados de un mínimo de condiciones políticas, jurídicas y administrativas, que les permita asumir algunas de las funciones del gobierno nacional, haciendo parte de un Estado unitario.” (2003: 125).

Francisco Gutiérrez Sanín (2010) define como escenario de análisis de la descentralización lo que Tilly (1985) define como problema de control territorial a cargo del Estado. En ello explica que el Estado puede emprender relaciones de distinta naturaleza con las élites y poderes regionales y locales, entre las cuales menciona desde las más flexibles, como la de "dejar hacer, ceder ante ellas", a las más restrictivas, definidas como "cooptadas o quebradas en su poder para ser remplazadas por otras conectadas orgánicamente con el Estado". Entre las variadas posibilidades de esa relación se emprendieron las reformas descentralizadoras en Colombia, las cuales, siendo necesarias, Gutiérrez Sanín afirma que generaron un cambio profundo en la estructura del poder territorial del Estado y una confluencia contingente de factores, haciendo de esas reformas un motor de transformación sobre la manera en que se intermediaba la relación entre el poder central y las élites regionales y locales. 
Gutiérrez explica que el resultado para el caso colombiano es una descentralización administrativa que transversaliza la modalidad fiscal, política y por servicios. La primera ubica su origen en la ley 14 de 1983 y la ley 12 de 1986, con una refrendación constitucional en 1991 a través de los artículos 356 al 364. La segunda se inicia en 1986 con la elección popular de alcaldes y gobernadores, seguida de la expedición de la ley 11 de 1986 regulatoria del Estatuto Básico de la Administración Municipal, la cual encontraría amplia refrendación constitucional en 1991 y legislación posterior, como se ejemplifica con la expedición del Decreto Ley 1333 de 1986, la ley 136 de 1994 y la más reciente ley 1551 de 2012. Finalmente sobre la descentralización por servicios Gutiérrez destaca la aparición del Sistema General de Participación y el Sistema general de Regalías (2010: p. 17).

Potenciada en la esfera administrativa del poder público, actualmente la descentralización se especializa en la modalidad de servicios, por colaboración, y territorial, esta última, una de las mejores modalidades a partir de las cuales el poder municipal encontraría senderos de seguridad jurídica al amparo de la autonomía para poder alcanzar los fines del Estado Social de Derecho.

Sin ser incompatible con la centralización política que en su sentido estricto monopoliza las tareas y funciones públicas desde el Estado central (Rodríguez Rodríguez, 1994: 42), tiene plena acogida funcional en Colombia tanto desde su aspecto genérico, en el sentido de efectivizar el traslado de asuntos del poder central a entidades seccionales o locales, y en sentido técnico, con el traslado específico de competencias a autoridades regionales y locales (Vidal Perdomo: 97), algo promovido con intensidad en el ordenamiento jurídico desde la Constitución Política de 1991, y que como se verá, siendo una fortaleza en la transición de los POT en los municipios de Colombia, puede ser mejor explotada en la ordenación del territorio.

La descentralización definió con la Carta Política de 1991 la autogestión y la aproximación de la toma democrática de decisiones de la ciudadanía con los poderes locales y regionales, en un compromiso con la autonomía y la participación; es "atribución que se otorga a las personas jurídicas públicas distintas de la Nación, para autogobernarse mediante la radicación en ellas de ciertas facultades que ejercen autónomamente" (Younes Moreno, 1997: 85), lo que la hace más que un insumo de la democratización del Estado de Derecho, un requisito en la democratización de los gobiernos municipales. En este aspecto 
concluye Barberena Nisimblat (2010: p. 60): “(...) en lo relacionado con la apertura democrática, la descentralización se produjo un cambio significativo en la forma de hacer política y en la motivación general de la sociedad para intervenir en los asuntos locales, desde el proceso electoral, hasta otras formas de participar en la vida local".

El Departamento Nacional de Planeación de Colombia (2007) explica la descentralización como "una estrategia de organización del Estado para el eficiente cumplimiento de sus fines esenciales y para garantizar los derechos de la ciudadanía en cualquier parte del país, a través de la transferencia de poder político como de recursos y competencias del Gobierno nacional a las entidades territoriales", lo que es refrendado por la Red de iniciativas para la gobernabilidad, la democracia y el desarrollo territorial (2007: p. 10) cuando la explica como "un mecanismo distribuidor del poder político entre el centro y la periferia, entre el Estado central y las entidades territoriales, que en su conjunto conforman el Estado unitario reconocido constitucionalmente en el país desde 1886."

En ese panorama la descentralización se traduce en la capacidad de autogobierno y gestión, mediante la asignación de asuntos y competencias por parte de la Constitución Política y las leyes, en manos de fracciones territoriales que bajo la categoría de entidades territoriales que definen parte de la organización ejecutiva del Estado, reciben el nivel de autoridad suficiente para emprender la toma de decisiones mediante procesos participativos que aproximen la ciudadanía con la administración pública en su ámbito de acción local.

La descentralización comprendida así en el orden constitucional ofrece la fortaleza de un régimen dotado de autonomía para la gestión de los territorios en Colombia. La autonomía constituye el núcleo esencial del principio de descentralización, desde el cual, en palabras de la Corte Constitucional al definir la autonomía, sostiene: "es expresión de dos principios constitucionales de la mayor significación, como son la consagración del municipio como la entidad fundamental del ordenamiento territorial y el ejercicio de las competencias asignadas conforme a los principios de coordinación, concurrencia y subsidiaridad (CP arts 288 y 311)" (Corte Constitucional de la República de Colombia, 2010: C - 149).

De lo anterior se sigue que la descentralización implica la transferencia de competencias y facultades del Estado establecidas por la 
Constitución y la ley que materializada en la modalidad territorial, también es posible en modalidad por colaboración y por servicios, lo que exige el despliegue de competencias que pueden ser ejercidas gracias a la autonomía como capacidad de las personas jurídicas del orden administrativo para el cumplimiento de la función administrativa.

La descentralización como promotora de autonomía persigue viabilizar el cumplimiento de los fines del Estado Social de Derecho, y ello es una labor irrenunciable a la luz del mandato constitucional para la función administrativa (Constitución Política, 1991: artículo 209): "la función administrativa está al servicio de los intereses generales y se desarrolla con fundamento en los principios de igualdad, moralidad, eficacia, economía, celeridad, imparcialidad y publicidad, mediante la descentralización, la delegación y la desconcentración de funciones."

\section{EL APOYO DE LOS PRINCIPIOS DEL ARTÍCULO 288 CONSTITUCIONALALADESCENTRALIZACIÓN}

Desde el enunciado constitucional debe reiterarse que la descentralización en su modalidad territorial encuentra la más propicia plataforma para la mejor estructuración y funcionamiento del Estado colombiano. Se sostiene lo anterior a partir de la preponderancia depositada en el Municipio como entidad fundamental de la organización del Estado, también porque el ordenamiento jurídico ha fortalecido las bases jurídicas para que dicha entidad territorial sea la principal encargada del cumplimiento de la función pública, razón que impulsa la adecuada y expresa asignación de competencias en el ámbito nacional. Esa asignación esta salvaguardada por un conjunto de principios jurídicos con amplio desarrollo legal y jurisprudencial, lo que genera el escenario propicio para una gobernabilidad local a partir de la capacidad reglamentaria del gobierno municipal, especialmente con los POT. En ello la ley 489 de 1998 (artículo 7) promueve:

En consecuencia procurará desarrollar disposiciones y normas que profundicen en la distribución de competencias entre los diversos niveles de la administración siguiendo en lo posible el criterio de que la prestación de los servicios corresponda a los municipios, el control sobre dicha prestación a los departamentos y la definición de planes, políticas y estrategias a la Nación. Igualmente al interior de las entidades nacionales descentralizadas el gobierno velará porque se establezcan disposiciones de delegación y 
desconcentración de funciones, de modo tal que sin perjuicio del necesario control administrativo los funcionarios regionales de tales entidades posean y ejerzan efectivas facultades de ejecución presupuestal, ordenación del gasto, contratación y nominación, así como de formulación de los anteproyectos de presupuesto anual de la respectiva entidad para la región sobre la cual ejercen su función.

La difícil función de la prestación de los servicios y la garantía de las necesidades básicas recae en el Municipio como entidad fundamental, pero en el marco descentralizado no es una función exclusiva o excluyente en la medida que la misma legislación nacional la ha enriquecido con una serie de principios que facilitan su cumplimiento, ellos son el principio de coordinación, el principio de concurrencia, el principio de subsidiariedad, y el principio de complementariedad. La Corte Constitucional, en la sentencia C- 149 de 2010, ha definido el concepto de estos tres principios de la siguiente manera:

El principio de coordinación, a su vez, tiene como presupuesto la existencia de competencias concurrentes entre distintas autoridades del Estado, lo cual impone que su ejercicio se haga de manera armónica, de modo que la acción de los distintos órganos resulte complementaria y conducente al logro de los fines de la acción estatal. Esa coordinación debe darse desde el momento mismo de la asignación de competencias y tiene su manifestación más clara en la fase de ejecución de las mismas.

El principio de concurrencia parte de la consideración de que, en determinadas materias, la actividad del Estado debe cumplirse con la participación de los distintos niveles de la Administración. Ello implica, en primer lugar, un criterio de distribución de competencias conforme al cual las mismas deben atribuirse a distintos órganos, de manera que se garantice el objeto propio de la acción estatal, sin que sea posible la exclusión de entidades que, en razón de la materia estén llamadas a participar. De este principio, por otra parte, se deriva también un mandato conforme al cual las distintas instancias del Estado deben actuar allí donde su presencia sea necesaria para la adecuada satisfacción de sus fines, sin que puedan sustraerse de esa responsabilidad. 
El principio de subsidiariedad, finalmente, corresponde a un criterio, tanto para la distribución y el ejercicio de las competencias. Desde una perspectiva positiva significa que la intervención del Estado, y la correspondiente atribución de competencias, debe realizarse en el nivel más próximo al ciudadano, lo cual es expresión del principio democrático y un criterio de racionalización administrativa, en la medida en que son esas autoridades las que mejor conocen los requerimientos ciudadanos. A su vez, en su dimensión negativa, el principio de subsidiariedad significa que las autoridades de mayor nivel de centralización sólo pueden intervenir en los asuntos propios de las instancias inferiores cuando estas se muestren incapaces o sean ineficientes para llevar a cabo sus responsabilidades.

Esta misma corporación en la Sentencia C-1051 de 2001 se ha manifestado sobre el alcance de estos principios estipulados en el artículo 288 de la Constitución Política de 1991, el artículo 27 de la ley 1454 de 2011, el artículo 6 de la ley 489 de 1998, el artículo 4 de la ley 1551 de 2012, el artículo 3 de la ley 1523 de 2013, de la siguiente manera:

El artículo 288 de la Constitución establece que las competencias atribuidas a los distintos niveles territoriales deben ser ejercidas conforme a los principios de coordinación, concurrencia y subsidiariedad, atendiendo a los lineamientos constitucionales y legales. El primer principio, indica que las autoridades administrativas deben coordinar sus actuaciones para el adecuado cumplimiento de los fines del Estado (art. 209 C.P.), coordinación que debe darse, tanto entre las entidades territoriales, como entre estas y la Nación. El principio de concurrencia implica un proceso de participación entre la Nación y las entidades territoriales, de modo que ellas intervengan en el "diseño y desarrollo de programas y proyectos dirigidos a garantizar el bienestar general y el mejoramiento de la calidad de vida, pues sólo así será posible avanzar en la realización efectiva de principios también de rango constitucional, como por ejemplo el de descentralización y autonomía territorial." El principio de subsidiariedad consiste en que sólo cuando la entidad territorial no pueda ejercer determinadas funciones en forma independiente, puede apelar a niveles superiores (el 
departamento o la Nación), para que estos asuman el ejercicio de esas competencias.

De esos principios el de coordinación genera unas consecuencias fundamentales en el sentido de que para preservar el interés nacional y el principio unitario, le corresponde al legislador establecer las condiciones básicas del ejercicio de la autonomía territorial, y definir, respetando el principio de subsidiariedad, las competencias del orden nacional que deberán desarrollarse conforme al principio de coordinación, que presupone unas reglas uniformes y una pautas de acción que, sin vaciar de contenido el ámbito de autonomía territorial, permitan una armonización de funciones.

El principio de concurrencia refleja en su contenido la exigencia de una participación conjunta de los distintos niveles territoriales, cuando el asunto en cuestión trasciende el interés exclusivamente local o regional y convoca a las diferentes entidades territoriales para hacer frente en el cumplimiento de la respectiva función para la cual las llama la normativa. Este sentido se refleja igualmente en el Auto 383 de 2010 de la Corte Constitucional que expresa: "La regla general es que se debe dar aplicación al principio de concurrencia, de modo que en principio, todos los niveles territoriales deben confluir en la formulación, ejecución y evaluación de las políticas públicas (...); en tal sentido, todas las instancias territoriales (de los órdenes nacional, departamental y municipal) deben realizar los esfuerzos necesarios para garantizar los derechos constitucionales (...).”

Finalmente, sobre la subsidiariedad es pertinente citar la disposición del artículo 3, numeral 14, de la ley 1523 de 2012:

La subsidiariedad puede ser de dos tipos: la subsidiariedad negativa, cuando la autoridad territorial de rango superior se abstiene de intervenir el riesgo y su materialización en el ámbito de las autoridades de rango inferior, si estas tienen los medios para hacerlo. La subsidiariedad positiva, impone a las autoridades de rango superior, el deber de acudir en ayuda de las autoridades de rango inferior, cuando estas últimas, no tengan los medios para enfrentar el riesgo y su materialización en desastre o cuando esté en riesgo un valor, un interés o un bien jurídico protegido relevante para la autoridad superior que acude en ayuda de la entidad afectada. 


\section{LAS COMPETENCIAS TERRITORIALES EN LA DESCENTRALIZACIÓN}

Los principios que amparan el cumplimiento de la función pública de la entidad territorial municipal encargada de proferir la normativa para el ordenamiento territorial, confluyen en la regulación de competencias como materia que en nuestro orden jurídico está en proceso de construcción, y que por lo tanto, es un referencial incompleto y en definición para el adecuado ejercicio del gobierno municipal. No obstante el reconocimiento que hace la descentralización administrativa territorial del Municipio, asegura que esa entidad cuente con las competencias expresas en la materia por vía directa de la Constitución, tal como se define en los artículos 311 a 321, especialmente las disposiciones de los artículos 311,313 y 318 .

ARTÍCULO 311. Al municipio como entidad fundamental de la división político administrativa del Estado le corresponde prestar los servicios públicos que determine la ley, construir las obras que demande el progreso local, ordenar el desarrollo de su territorio, promover la participación comunitaria, el mejoramiento social y cultural de sus habitantes y cumplir las demás funciones que le asignen la Constitución y las leyes.

ARTÍCULO 313. Corresponde a los concejos:

1. Reglamentar las funciones y la eficiente prestación de los servicios a cargo del municipio.

2. Adoptar los correspondientes planes y programas de desarrollo económico y social y de obras públicas.

(...)

5. Dictar las normas orgánicas del presupuesto y expedir anualmente el presupuesto de rentas y gastos.

6. Determinar la estructura de la administración municipal y las funciones de sus dependencias; las escalas de remuneración correspondientes a las distintas categorías de empleos; crear, a iniciativa del alcalde, establecimientos públicos y empresas industriales o comerciales y autorizar la constitución de sociedades de economía mixta.

7. Reglamentar los usos del suelo y, dentro de los límites que fije la ley, vigilar y controlar las actividades relacionadas con la construcción y enajenación de inmuebles destinados a vivienda. 
(...)

9. Dictar las normas necesarias para el control, la preservación y defensa del patrimonio ecológico y cultural del municipio.

10. Las demás que la Constitución y la ley le asignen.

ARTÍCULO 318 Con el fin de mejorar la prestación de los servicios y asegurar la participación de la ciudadanía en el manejo de los asuntos públicos de carácter local, los concejos podrán dividir sus municipios en comunas cuando se trate de áreas urbanas, y en corregimientos en el caso de las zonas rurales.

En cada una de las comunas o corregimientos habrá una junta administradora local de elección popular, integrada por el número de miembros que determine la ley, que tendrá las siguientes funciones:

1. Participar en la elaboración de los planes y programas municipales de desarrollo económico y social y de obras públicas.

2. Vigilar y controlar la prestación de los servicios municipales en su comuna o corregimiento y las inversiones que se realicen con recursos públicos.

3. Formular propuestas de inversión ante las autoridades nacionales, departamentales y municipales encargadas de la elaboración de los respectivos planes de inversión.

4. Distribuir las partidas globales que les asigne el presupuesto municipal.

5. Ejercer las funciones que les deleguen el concejo y otras autoridades locales. Las asambleas departamentales podrán organizar juntas administradoras para el cumplimiento de las funciones que les señale el acto de su creación en el territorio que este mismo determine.

Si bien se comparte la idea de la atribución expresa y directa de competencias al Municipio por parte de la Constitución Política, la ausencia de un referente competencial legal expreso para el Ordenamiento Territorial, hace que sobre las mismas competencias constitucionales se genere la incertidumbre de definir cuáles son propiamente territoriales, o al menos regulables a través de los "planes" en los que se debe definir el ordenamiento territorial municipal que hasta hace un año estaba en transición en las plenarias de los Concejos. Esto sin duda lleva a que las citadas competencias puedan ser vistas como una 
mera enunciación ante la falta de taxatividad por la ausencia de una ley verdaderamente orgánica, mandato constitucional de la Constitución Política de 1991 en sus artículos 151 y 288.

No obstante no debe perderse de vista que el Municipio es la entidad territorial delegada por la Constitución Política para la ordenación de su territorio, y con ello, de realizar la planeación social, económica, física y ambiental. Si bien esa entidad territorial cuenta en las disposiciones de la Carta Política con la asignación mínima, más no completa, de las competencias generales para la Planeación, y de adelantar Políticas Públicas por medio de los planes desarrollados por la legislación, la descentralización territorial remite al Municipio las competencias que no estén asignadas por ley. Así, al alcance del artículo 7 de la ley 489 de 1998 debe concordarse con el fijado por la ley 1454 de 2011 que refuerza en el Municipio la proyección de una organización territorial fortalecida desde lo local por medio de la asignación de la cláusula residual de competencias apoyada desde los principios: "Artículo 28. (...) Parágrafo. Los municipios son titulares de cualquier competencia que no esté atribuida expresamente a los departamentos o a la Nación. Cuando el respectivo municipio no esté en capacidad de asumir dicha competencia solicitará la concurrencia del departamento y la Nación".

Conforme a las competencias para el ordenamiento del territorio, el Municipio es y será la entidad primigenia de la organización del Estado. En él radica la base de la descentralización territorial, lo que devela que el referencial jurídico para la organización territorial ha existido antes de la promulgación de la Constitución de 1991 que ahora lo formaliza como entidad fundamental dotado de instrumentos de efectivización regulados por leyes, los cuales le permiten desarrollar esas competencias, como es el caso del POT para los asuntos espaciales, ambientales, patrimoniales y de gestión de riesgo. Pero al mismo tiempo se devela la ausencia de un régimen de competencias para la organización del territorio a cargo de las entidades territoriales distintas al Municipio, a lo cual defenderemos el amparo axiológico de los principios de coordinación, concurrencia, subsidiariedad y complementariedad.

Es por ello que el referencial normativo ha fortalecido al municipio en la historia reciente frente a la obligación de ordenar el territorio, y en torno a él, venga supliendo desde la postura de una ley orgánica de ordenamiento territorial dispersa y vaga, el régimen de competencias de planeación territorial de las demás entidades territoriales no encargadas de la ciudad como objeto de planeación. 
Sin embargo, es la misma ley 1454 de 2011 la que fortalece la función municipal en materia territorial cuando dispone como competencias territoriales "a) Formular y adoptar los planes de ordenamiento del territorio; b) Reglamentar de manera específica los usos del suelo, en las áreas urbanas, de expansión y rurales, de acuerdo con las leyes; c) Optimizar los usos de las tierras disponibles y coordinar los planes sectoriales, en armonía con las políticas nacionales y los planes departamentales y metropolitanos."

Con ellas no se contrarresta la relevancia de las disposiciones municipales, y por el contrario, se reitera con base en la coordinación, la prelación de sus disposiciones en el ámbito municipal atendiendo a referenciales de entidades territoriales. La preponderancia de la competencia municipal en la materia se reiteró con la expedición de la ley 1551 de 2012 sobre actualización del régimen municipal, atendiendo el mandato legal de la ley 1454 de 2011 en su artículo 37: "El Gobierno Nacional presentará al Congreso las iniciativas de reformas legislativas correspondientes a la expedición del régimen especial para los departamentos, la reforma del régimen municipal orientada por las prescripciones del artículo 320 de la Constitución Política y la reforma de la legislación en materia de áreas metropolitanas."

Específicamente del referencial jurídico dispuesto en la Carta de 1991 sobre el Municipio, se desprenden los desarrollos legales que sirven de referenciales para el ordenamiento territorial en todas las esferas previstas por la Ley 388 de 1997. Dispone el artículo 313 en el numeral 1: "Reglamentar las funciones y la eficiente prestación de los servicios a cargo del municipio", a lo que se articula la ley 142 de 1994 con el régimen de los servicios públicos domiciliarios; el numeral 2 "Adoptar los correspondientes planes y programas de desarrollo económico y social y de obras públicas", que tiene por referencial la ley 152 de 1994 sobre planes de desarrollo; el numeral 5: "Dictar las normas orgánicas del presupuesto y expedir anualmente el presupuesto de rentas y gastos", lo que es fundamental para la ejecución y efectivización de la política, soportada en la ley 225 de 1995 como ley orgánica de presupuesto.

Igualmente, el artículo 313 de la Carta dispone en el numeral 7 "Reglamentar los usos del suelo y, dentro de los límites que fije la ley, vigilar y controlar las actividades relacionadas con la construcción y enajenación de inmuebles destinados a vivienda", articulando referenciales legislativos como la ley 9 de 1989, la ley 2 y 3 de 1991 para vivienda, la ley 388 de 1997, y la ley 1454 de 2011. Adicionalmente se 
deben mencionar expresamente las disposiciones del capítulo primero de la ley 136 de 1994 que reitera al Municipio como la entidad territorial fundamental de la división político administrativa del Estado (Congreso de la República de Colombia, 1996: Ley 136 artículo 1), y señala como funciones referenciales para la Política Pública de planeación urbana:

1. Administrar los asuntos municipales y prestar los servicios públicos que determine la ley.

2. Ordenar el desarrollo de su territorio y construir las obras que demande el Progreso municipal.

3. Promover la participación comunitaria y el mejoramiento social y cultural de sus habitantes.

4. Planificar el desarrollo económico, social y ambiental de su territorio, de conformidad con la ley y en coordinación con otras entidades.

5. Solucionar las necesidades insatisfechas de salud, educación, saneamiento ambiental, agua potable, servicios públicos domiciliarios, vivienda recreación y deporte, con especial énfasis en la niñez, la mujer, la tercera edad y los sectores discapacitados, directamente $\mathrm{y}$, en concurrencia, complementariedad y coordinación con las demás entidades territoriales y la Nación, en los términos que defina la ley.

6. Velar por el adecuado manejo de los recursos naturales y del medio ambiente, de conformidad con la ley.

(...) (Congreso de la República de Colombia, 1996: Ley 136 artículo 3).

Junto a la ley 136 de 1994 aparece la ley 1469 de 2011 por medio de la cual se adoptan medidas para promover la oferta de suelo urbanizable y se adoptan otras disposiciones para promover el acceso a la vivienda; y más tarde, la ya citada ley 1551 de 2012 actualiza y reitera las funciones municipales de la ley 136 así:

1. Administrar los asuntos municipales y prestar los servicios públicos que determine la ley.

2. Elaborar los planes de desarrollo municipal, en concordancia con el plan de desarrollo departamental, los planes de vida de los territorios y resguardos indígenas, incorporando las visiones de las minorías étnicas, de las organizaciones comunales y de los grupos de población vulnerables presentes en su 
territorio, teniendo en cuenta los criterios e instrumentos definidos por la Unidad de Planificación de Tierras Rurales y Usos Agropecuarios -UPRA-, para el ordenamiento y el uso eficiente del suelo rural, los programas de desarrollo rural con enfoque territorial, y en armonía con el Plan Nacional de Desarrollo, según la ley orgánica de la materia.

Los planes de desarrollo municipal deberán incluir estrategias y políticas dirigidas al respeto y garantía de los Derechos Humanos y del Derecho Internacional Humanitario;

3. Promover el desarrollo de su territorio y construir las obras que demande el progreso municipal. Para lo anterior deben tenerse en cuenta, entre otros: los planes de vida de los pueblos y comunidades indígenas y los planes de desarrollo comunal que tengan los respectivos organismos de acción comunal.

(...)

9. Formular y adoptar los planes de ordenamiento territorial, reglamentando de manera específica los usos del suelo en las áreas urbanas, de expansión y rurales, de acuerdo con las leyes y teniendo en cuenta los instrumentos definidos por la UPRA para el ordenamiento y el uso eficiente del suelo rural. Optimizar los usos de las tierras disponibles y coordinar los planes sectoriales en armonía con las políticas nacionales y los planes departamentales y metropolitanos. Los Planes de Ordenamiento Territorial serán presentados para revisión ante el Concejo Municipal o Distrital cada 12 años.

10. Velar por el adecuado manejo de los recursos naturales y del ambiente, de conformidad con la Constitución y la ley. (...)

14. Autorizar y aprobar, de acuerdo con la disponibilidad de servicios públicos, programas de desarrollo de Vivienda ejerciendo las funciones de vigilancia necesarias.

15. Incorporar el uso de nuevas tecnologías, energías renovables, reciclaje y producción limpia en los planes municipales de desarrollo.

(...)

18. Celebrar convenios de uso de bienes públicos y/o de usufructo comunitario con los cabildos, autoridades y organizaciones indígenas y con los organismos de acción comunal y otros organismos comunitarios. 
19. Garantizar la prestación del servicio de agua potable y saneamiento básico a los habitantes de la jurisdicción de acuerdo con la normatividad vigente en materia de servicios públicos domiciliarios.

(...)

22. Las demás que señalen la Constitución y la ley.

23. En materia de vías, los municipios tendrán a su cargo la construcción y mantenimiento de vías urbanas y rurales del rango municipal. Continuarán a cargo de la Nación, las vías urbanas que formen parte de las carreteras nacionales, y del Departamento las que sean departamentales.

El numeral 9 del artículo 313 establece "Dictar las normas necesarias para el control, la preservación y defensa del patrimonio ecológico y cultural del municipio" referenciado en la ley 99 de 1993 y todo lo que se desprende del SINA, y en la ley 397 de 1997 y la ley 1185 de 2008 como ley reformatoria para el patrimonio.

\section{CONCLUSIÓN}

La transición de los POT en los municipios colombianos pone de manifiesto la forma en que se ha estructurado un Estado que logró dejar en el pasado una profunda división entre sectores que enfrentados buscaban imponer por la fuerza un modelo de organización polarizado en sus finalidades. Si bien de dicha polarización aún se viven intensas y dolorosas secuelas como la inequidad, la mala distribución de la tierra, el consecuente conflicto armado interno, y el desplazamiento de población, debe reconocerse que con la Constituyente de 1991 Colombia permitió leerse en un contexto de transformación mediado por la descentralización.

La descentralización ha facilitado la distribución del poder, no solo en el Estado, sino en la población que se hace partícipe de los procesos de toma de decisiones de las esferas públicas en las cuales se define el cumplimiento de los fines del Estado, que en últimas, garantizan la satisfacción de las necesidades locales en los cuales se ubica y habita esa población.

Con la descentralización del poder administrativo, Colombia concretó en los escenarios urbanos a cargo del Municipio, la estructura administrativa de un Estado que avanza en medio de ambigüedades competenciales que no generan la suficiente seguridad jurídica de la 
acción estatal. Quiere decir, a la buena estructura administrativa promovida con la asignación de potestades decisorias en los territorios donde se presentan las necesidades, hemos depositado en el Municipio la responsabilidad del cumplimiento de la función pública que aunque ambigua, dispersa e incompleta en la asignación de competencias, no ha mermado la capacidad autonómica del Municipio como gestor de políticas en la ciudad.

\section{REFERENCIAS BIBLIOGRÁFICAS}

Barberena, V. (2010) Las preguntas sin respuesta de la descentralización: la encrucijada y los nuevos caminos. En: 25 años de la descentralización en Colombia. Bogotá: Konrad Adenauer Stiftung. pp. 55-88.

Constitución Política de Colombia (1991).

Corte Constitucional de la República de Colombia(2010)Auto 383

Corte Constitucional de la República de Colombia (2001) Sentencia C 1051

Corte Constitucional de la República de Colombia (2010) Sentencia C 149

Congreso de la República de Colombia (1997) Ley 388

Congreso de la República de Colombia (1998) Ley 489

Congreso de la República de Colombia (1993) Ley 99

Congreso de la República de Colombia (1994) Ley 154

Congreso de la República de Colombia (1994) Ley 142

Congreso de la República de Colombia (2011) Ley 1454

Congreso de la República de Colombia (2012) Ley 1551

Congreso de la República de Colombia (2012) Ley 1523

Congreso de la República de Colombia (1999) Ley 507 
Congreso de la República de Colombia (1999) Ley 564

Congreso de la República de Colombia (2002) Ley 932

Gutiérrez Sanín, F. (2010) Instituciones y Territorio: La descentralización en Colombia. En: 25 años de la descentralización en Colombia. Bogotá: Konrad Adenauer Stiftung. pp. 55-88. pp. $11-54$

Pening Gaviria, J. P. (2003) Evaluación del proceso de descentralización en Colombia. En: Economía y Desarrollo. Vol. 2. N. 1.pp. 123 - 149

Vidal Perdomo, J. (2004) Derecho Administrativo. Bogotá: Editorial Temis

Younes Moreno, D. (1997) Derecho Constitucional Colombiano. 3rd Ed. Bogotá: Legis

Pedraza López, B. (2007) Veinte años no son nada. En: RINDE: Red de iniciativas para la gobernabilidad, la democracia y el desarrollo territorial (2007) 20 años de la descentralización en Colombia: presente y futuro. Bogotá

Departamento Nacional de Planeación de Colombia (2007) Fortalecer la descentralización y adecuar el ordenamiento territorial. Bogotá. Disponible On line en: https://www.dnp.gov.co/Portals/0/archivos/ documentos/2019/Documentos/Cartilla\%20descentralizacion\%2002.pdf 